\title{
Splanchnic Glucose and Amino Acid Metabolism in Obesity
}

\author{
Philip Felig, John Wahren, Rosa Hendler, and T. Brundin \\ From the Department of Internal Medicine, Yale University School of \\ Medicine, New Haven, Connecticut 06510, and the Department of Clinical \\ Physiology of the Karolinska Institute at the Serafimer Hospital, \\ Stockholm, Sweden
}

A B S T R A C T Arterial concentrations and splanchnic exchange of glucose, lactate, pyruvate, glycerol, free fatty acids, and individual acidic and neutral amino acids were determined in obese and nonobese control subjects in the basal state and during a $45 \mathrm{~min}$ infusion of glucose. Glucose was administered to the controls at a rate $(2 \mathrm{mg} / \mathrm{kg} / \mathrm{min} ; 144 \pm 4 \mathrm{mg} / \mathrm{min})$ known to inhibit splanchnic glucose output without influencing peripheral glucose utilization. The obese subjects received glucose at two dose levels (75 and $150 \mathrm{mg} / \mathrm{min}$ ) which simulated either the rise in insulin or the inhibition in splanchnic glucose production observed in the controls.

In the basal state splanchnic glucose production did not differ significantly between obese and control subjects. However splanchnic uptake of lactate, glycerol, alanine, free fatty acids, and oxygen was 50-160\% greater in obese subjects. Splanchnic uptake of glucose precursors could account for $33 \%$ of hepatic glucose output in the obese group as compared to $19 \%$ in controls. The increase in alanine and lactate uptake was due in part, to a $50 \%$ increase in splanchnic fractional extraction.

Administration of glucose to the control subjects $144 \pm 4 \mathrm{mg} / \mathrm{min}$ ) resulted in a $50-60 \%$ increment in arterial insulin and a $75 \%$ reduction in splanchnic glucose output. In the obese group, infusion of glucose at a rate of $75 \mathrm{mg} / \mathrm{min}$ resulted in an equivalent rise in arterial insulin, but was accompanied by a less than $40 \%$ inhibition in splanchnic glucose output. Glucose infusion at a rate of $150 \mathrm{mg} / \mathrm{min}$ in the obese resulted in a $75 \%$ reduction in splanchnic glucose output which was equivalent to that observed in controls, but was accom-

Dr. Felig is recipient of a Research Career Development Award (AM 70219) from the National Institutes of Health. Reccived for publication 3 August 1973 and in revised form 26 September 1973. panied by a significantly greater rise (100-200\%) in arterial insulin.

It is concluded that in obesity $(a)$ despite basal hyperinsulinemia, splanchnic uptake of glucose precursors is increased, the relative contribution to total glucose release attributable to gluconeogenesis being $70 \%$ higher than in controls; $(b)$ infusion of glucose at rates causing equivalent increases in arterial insulin induces a smaller inhibition in splanchnic glucose output than in controls; (c) infusion of glucose at rates causing comparable inhibition in splanchnic glucose output is accompanied by a disproportionately greater increase in endogenous insulin than in controls. These data are compatible with hepatic resistance to insulin in obesity.

\section{INTRODUCTION}

Obesity has been characterized by a variety of abnormalities in carbohydrate and insulin metabolism. Augmented insulin secretion $(1,2)$, decreased responsiveness of fat and muscle tissue to insulin $(3,4)$, and an increased incidence of diabetes (5) have been well documented. Despite these clear indications of altered carbohydrate homeostasis, the contribution of the liver to these metabolic changes has not been established. Specifically, direct observations of glucose production and uptake of precursor substrates by the splanchnic bed have not been previously reported in obese subjects. Furthermore the effect of obesity on hepatic responsiveness to increments in endogenous insulin has not been determined. Our interest in examining these parameters was stimulated by recent observations from our laboratories, in confirmation of earlier work by Madison in dogs (6), indicating that the liver is the primary site of action of small increases in endogenous insulin in normal subjects (7). In addition we have demonstrated that augmented gluconeogenesis in diabetes is a conse- 
quence of altered hepatic rather than peripheral processes (8).

In the present study the hepatic venous catheter technique has been employed to determine the effects of obesity on splanchnic exchange of glucose and glucose precursors in the basal, postabsorptive state. In addition we have examined splanchnic sensitivity to endogenous insulin by infusing glucose in nonobese control subjects at a rate $(2 \mathrm{mg} / \mathrm{kg} / \mathrm{min})$ known to affect splanchnic glucose output without influencing peripheral glucose utilization ( 7$)$. The response was then compared with that observed in obese subjects in whom glucose was infused at two dose levels (75 and $150 \mathrm{mg} / \mathrm{min}$ ) which simulated either the rise in insulin or the change in hepatic glucose output observed in the controls. In this manner the splanchnic response to comparable increments in arterial insulin and the insulin rise associated with a comparable inhibition of splanchnic glucose output was determined for the obese and control subjects.

\section{METHODS}

Subjects and procedures. The obese group consisted of 13 male subjects who were in good health, and had no history or evidence of diabetes, as indicated by an absolute glucose disappearance rate $(K)$ of $1.3 \% / \mathrm{min}$ or greater on intravenous glucose tolerance testing (9). Clinical data for each of the subjects are presented in Table I. Five of the subjects were studied on two separate occasions. The control group consisted of 12 healthy, adult male volunteers $21-48 \mathrm{yr}$ of age, weighing $58-82 \mathrm{~kg}(71.3 \pm 2 \mathrm{~kg}$, mean $\pm \mathrm{SE}$ ), all of whom were within $10 \%$ of ideal weight (as determined by Metropolitan Life Insurance Tables, 1959). For at least $1 \mathrm{wk}$ before study all of the subjects ingested a weight-maintaining diet containing $40 \%$ carbohydrate. The nature, purpose, and possible risks involved in the study were carefully explained to all subjects before obtaining their voluntary consent to participate.

The studies were performed in the morning after an overnight (12-14 h) fast. Teflon catheters were inserted percutaneously into a brachial artery and an antecubital vein. A Cournand catheter (no. 7 or 8 ) was then inserted percutaneously into an antecubital vein and advanced under fluoroscopic control to a right-sided hepatic vein. The tip of the catheter was placed $3-4 \mathrm{~cm}$ from the wedge position and its location was checked repeatedly by fluoroscopy during the study. Patency of the catheters was maintained throughout the study by flushing with saline intermittently. Heparin was not employed.

After the catheters were in place, simultaneous arterial and hepatic venous blood samples were drawn repeatedly at 10-15-min intervals until three to four sets of simultaneous samples had been obtained from each subject. In the control group glucose was then infused intravenously as a $5 \%$ solution at a rate of $2 \mathrm{mg} / \mathrm{kg} / \mathrm{min}(144 \pm 4 \mathrm{mg} / \mathrm{min}$, mean $\pm \mathrm{SE}$ ) for $45 \mathrm{~min}$. In the obese group, five of the subjects (S. G., A. F., K. B., S. M., and O. O.) were infused with glucose at a rate of $75 \mathrm{mg} / \mathrm{min}$ for $45 \mathrm{~min}$. A second study was subsequently performed in these five obese subjects at which time glucose was infused at a rate of 150 $\mathrm{mg} / \mathrm{min}$ for $45 \mathrm{~min}$. Blood samples were obtained from the
TABLE I

Clinical Data on Obese Subjects

\begin{tabular}{lcccc}
\hline Subject & Age & Height & Weight & $\begin{array}{c}\text { Ideal } \\
\text { weight* }\end{array}$ \\
\hline & $y r$ & $c m$ & $k g$ & $\%$ \\
L. O. & 29 & 182 & 155 & 213 \\
G. A. & 36 & 169 & 135 & 216 \\
C. B. & 26 & 180 & 101 & 141 \\
S. G. & 31 & 177 & 102 & 147 \\
S. L. & 24 & 186 & 105 & 141 \\
S. Gu. & 32 & 178 & 96 & 134 \\
A. F. & 25 & 190 & 117 & 148 \\
K. B. & 27 & 180 & 108 & 151 \\
S. M. & 41 & 178 & 101 & 146 \\
O. O. & 31 & 180 & 107 & 150 \\
A. H. & 18 & 180 & 116 & 163 \\
S. Mu. & 29 & 178 & 99 & 138 \\
T. W. & 28 & 175 & 108 & 159 \\
\hline
\end{tabular}

* Based on Metropolitan Life Insurance Tables, 1959. $\ddagger$ Studied on two occasions.

arterial and hepatic venous catheters every 5-8 min after the start of the glucose infusion. Eight of the obese subjects were studied in the basal state only.

Analyses. The methods employed for the determination of hepatic blood flow and for measurement of blood glucose, lactate, pyruvate, glycerol and oxygen, individual acidic and neutral plasma amino acids, and plasma insulin and glucagon, have been described previously $(7,8,10,11)$. In five of the obese subjects splanchnic exchange of alanine in the basal state was determined using whole blood for analysis (12). Free fatty acids were determined by the gas chromatographic procedure of Hagenfeldt (13).

The Student's $t$ test and the analysis of variance were employed in the statistical analyses (14). Splanchnic exchange was calculated from the arterio-hepatic venous differences and the estimated hepatic blood flow. Data in the text, tables, and figures are presented as the mean $\pm S E$.

\section{RESULTS}

Artcrial concentrations. The arterial concentrations of substrates and hormones in the basal state are shown in Table II. The concentrations of glucose and lactate were comparable in the obese and control groups. However, in accord with previous studies $(15,16)$, eleva-

TABLE II

Arterial Concentrations of Substrates and Hormones in Obese and Control Subjects in the Basal State*

\begin{tabular}{lccc}
\hline & Obese & Control & $P \ddagger$ \\
\hline Glucose, $\mathrm{mmol} / \mathrm{liler}$ & $4.35 \pm 0.11$ & $4.27 \pm 0.09$ & $\mathrm{NS}$ \\
Lactate, $\mathrm{mmol} / \mathrm{liter}$ & $0.72 \pm 0.06$ & $0.61 \pm 0.05$ & $\mathrm{NS}$ \\
Pyruvate, $\mu \mathrm{mol} / \mathrm{liter}$ & $82 \pm 5$ & $65 \pm 3$ & $<0.02$ \\
Glycerol, $\mu \mathrm{mol} / \mathrm{liler}$ & $85 \pm 6$ & $52 \pm 5$ & $<0.001$ \\
FFA, $\mathrm{mmol} / \mathrm{liter}$ & $1.000 \pm 0.169$ & $0.553 \pm 0.054$ & $<0.02$ \\
Insulin, $\mu \mathrm{U} / \mathrm{ml}$ & $31 \pm 4$ & $13 \pm 1$ & $<0.001$ \\
Glucagon, $\mathrm{pg} / \mathrm{ml}$ & $74 \pm 7$ & $80 \pm 13$ & $\mathrm{NS}$ \\
\hline
\end{tabular}

* Data represent the mean of two to three observations in each subject in both groups and are presented as mean $\pm \mathrm{SE}$.

$\ddagger$ Significance of difference between obese and control groups. 
TABLE III

Arterial Concentration and Splanchnic Exchange of Plasma Amino Acids in the Basal State in Obese and Control Subjects*

\begin{tabular}{|c|c|c|c|c|c|c|}
\hline & \multicolumn{3}{|c|}{ Arterial concentration } & \multicolumn{3}{|c|}{ Splanchnic exchange } \\
\hline & Obese & Controls & $P \ddagger$ & Obese & Controls & $P \ddagger$ \\
\hline & \multicolumn{3}{|c|}{$\mu \mathrm{mol} /$ liter } & \multicolumn{3}{|c|}{$\mu \mathrm{mol} / \mathrm{min}$} \\
\hline Taurine & $41 \pm 1$ & $40 \pm 3$ & NS & $-4.2 \pm 4.0$ & $0.9 \pm 2.4$ & NS \\
\hline Aspartic acid & $9 \pm 1$ & $14 \pm 3$ & NS & $-2.0 \pm 0.7$ & $1.1 \pm 1.3$ & NS \\
\hline Threonine & $125 \pm 12$ & $97 \pm 7$ & $<0.05$ & $17.0 \pm 2.8$ & $11.2 \pm 4.0$ & NS \\
\hline Serine & $122 \pm 10$ & $121 \pm 8$ & NS & $24.9 \pm 5.4$ & $22.5 \pm 5.7$ & NS \\
\hline Proline & $186 \pm 23$ & $163 \pm 24$ & NS & $4.9 \pm 3.3$ & $8.9 \pm 7.6$ & NS \\
\hline Citrulline & $40 \pm 3$ & $33 \pm 3$ & NS & $-12.5 \pm 2.5$ & $8.3 \pm 2.6$ & NS \\
\hline Glycine & $175 \pm 11$ & $187 \pm 13$ & NS & $16.3 \pm 4.2$ & $9.0 \pm 2.6$ & NS \\
\hline Alanine & $301 \pm 23$ & $187 \pm 15$ & $<0.001$ & $136.2 \pm 14.8$ & $58.2 \pm 9.8$ & $<0.001$ \\
\hline$\alpha$-Aminobutyrate & $23 \pm 1$ & $23 \pm 3$ & NS & $1.2 \pm 1.1$ & $1.4 \pm 1.1$ & NS \\
\hline Valine & $286 \pm 17$ & $215 \pm 12$ & $<0.005$ & $-3.6 \pm 2.3$ & $-2.7 \pm 8.3$ & NS \\
\hline Cystine & $135 \pm 5$ & $97 \pm 6$ & $<0.001$ & $0.2 \pm 2.9$ & $3.0 \pm 4.6$ & NS \\
\hline Methionine & $23 \pm 2$ & $18 \pm 1$ & $<0.025$ & $4.7 \pm 1.0$ & $4.3 \pm 1.7$ & NS \\
\hline Isoleucine & $72 \pm 5$ & $55 \pm 5$ & $<0.025$ & $-1.2 \pm 2.0$ & $-1.6 \pm 2.4$ & NS \\
\hline Lellcine & $143 \pm 10$ & $115 \pm 9$ & $<0.05$ & $-0.3 \pm 3.4$ & $-4.0 \pm 5.5$ & NS \\
\hline Tyrosine & $58 \pm 5$ & $45 \pm 3$ & $<0.025$ & $8.1 \pm 1.0$ & $6.5 \pm 2.3$ & NS \\
\hline Phenylalanine & $54 \pm 4$ & $41 \pm 3$ & $<0.025$ & $3.9 \pm 1.0$ & $3.3 \pm 1.3$ & NS \\
\hline
\end{tabular}

* Data are presented as the mean $\pm \mathrm{SE}$.

$\ddagger$ Significance of differences between obese and control subjects.

tions in plasma glycerol and free fatty acids (FFA) were noted in the obese subjects. An increment in plasma pyruvate was also observed in the obese group. As anticipated $(1,2)$, basal arterial insulin levels were two to threefold higher in the obese subjects as compared with controls. In contrast, basal glucagon concentration was similar in the two groups.

The arterial concentrations of individual plasma amino acids are given in Table III. Particularly noteworthy is the increment in arterial alanine, the key endogenous

TABLE IV

Splanchnic Exchange of Glucose, Precursor Substrates, FFA, and Oxygen in Obese and Control Subjects in the Basal State*

\begin{tabular}{lccc}
\hline & Obese & Control & $P_{+}^{+}$ \\
\hline Glucose, $\mathrm{mmol} / \mathrm{min}$ & $-\mathbf{1 . 1 0} \pm \mathbf{0 . 1 2}$ & $-1.23 \pm 0.11$ & $\mathrm{NS}$ \\
Lactate, $\mathrm{mmol} / \mathrm{min}$ & $\mathbf{0 . 3 8} \pm \mathbf{0 . 0 4}$ & $0.22 \pm 0.02$ & $<0.005$ \\
Pyruvate, $\mathrm{mmol} / \mathrm{min}$ & $0.004 \pm 0.011$ & $0.021 \pm 0.003$ & $\mathrm{NS}$ \\
Glycerol, $\mathrm{mmol} / \mathrm{min}$ & $\mathbf{0 . 1 0 5} \pm \mathbf{0 . 0 0 8}$ & $\mathbf{0 . 0 6 8} \pm 0.07$ & $<0.005$ \\
$\mathrm{FFA}, \mathrm{mmol} / \mathrm{min}$ & $0.259 \pm 0.053$ & $0.128 \pm 0.013$ & $<0.02$ \\
Oxygen, $\mathrm{ml} / \mathrm{min}$ & $93.6 \pm 7.7$ & $\mathbf{5 8 . 1} \pm 2.9$ & $<0.001$ \\
EHBF\&, $\mathrm{ml} / \mathrm{min}$ & $1,571 \pm 37$ & $1,359 \pm 51$ & $<0.05$
\end{tabular}

* Data represent the mean of two to three observations on each subject in both groups and are presented as the mean $\pm \mathrm{SE}$. Splanchnic exchange was calculated from arterio-hepatic venous differences and estimated hepatic blood flow. Negative values indicate net splanchnic release (e.g., glucose); positive values indicate a net splanchnic uptake.

$\ddagger$ Significance of difference between obese and control groups.

\& Estimated hepatic blood flow. glycogenic amino acid $(17,18)$. Increased levels of the branched chain amino acids (valine, leucine, and isoleucine) and of tyrosine, methionine, phenylalanine, threonine, and cystine were also noted in the obese subjects.

Splanchnic metabolism. Net splanchnic balance of glucose, lactate, pyruvate, FFA, and oxygen is shown in Table IV. The basal rate of splanchnic glucose ouptut, calculated as the product of the arterial-hepatic venous difference and hepatic blood flow, was slightly but not significantly lower in the obese group. Despite the similarity in net glucose release, significant increments were noted in the obese subjects with respect to splanchnic uptake of glucose-precursor substrates. Thus net uptake of lactate and glycerol was $50-75 \%$ higher in the obese group (Table IV). Inasmuch as the arterial concentration of lactate was not increased in the obese subjects, the increased uptake of this glucose precursor was a result of a $50 \%$ greater fractional extraction by the splanchnic vascular bed (Fig. 1).

Of the 16 plasma amino acids measured, consistent uptakes by the splanchnic bed were demonstrable in both groups for 7 amino acids: Alanine, threonine, serine, glycine, methionine, tyrosine, and phenylalanine (Table III). In accordance with previous observations (17), in both groups alanine uptake exceeded that of all other amino acids. Of note is the demonstration that splanchnic uptake of alanine in the obese subjects was $130 \%$ greater than in controls (Table III). This aug- 
mentation in splanchnic uptake was not only due to an increase in arterial concentration, but resulted also in part from a $50 \%$ greater rate of fractional extraction of this amino acid by the splanchnic bed (Fig. 1). The splanchnic exchange of other amino acids was not significantly different between the two groups.

In view of recent data indicating that blood cells contribute to splanchnic uptake of alanine (12), whole blood analyses in addition to plasma determinations were performed in five obese subjects. Splanchnic uptake of alanine from whole blood in the obese group (179 \pm 27 $\mu \mathrm{mol} / \mathrm{min}$ ) was significantly greater than in nonobese controls $(107 \pm 10 ; P<0.05)$.

In association with the augmented uptake of glucose precursors, an increase in splanchnic uptake of FFA and oxygen was observed in the obese group (Table IV). Hepatic blood flow was also slightly $(15 \%)$ higher in the obese subjects (Table IV).

Response to glucose infusion. In Table $\mathrm{V}$ the effect of intravenous administration of glucose on arterial levels of glucose, insulin, and glucagon and on splanchnic glucose production in the control and obese subjects is shown. In the control group infusion of glucose at a rate of $2 \mathrm{mg} / \mathrm{kg} / \mathrm{min}$ resulted in a maximal rise in mean

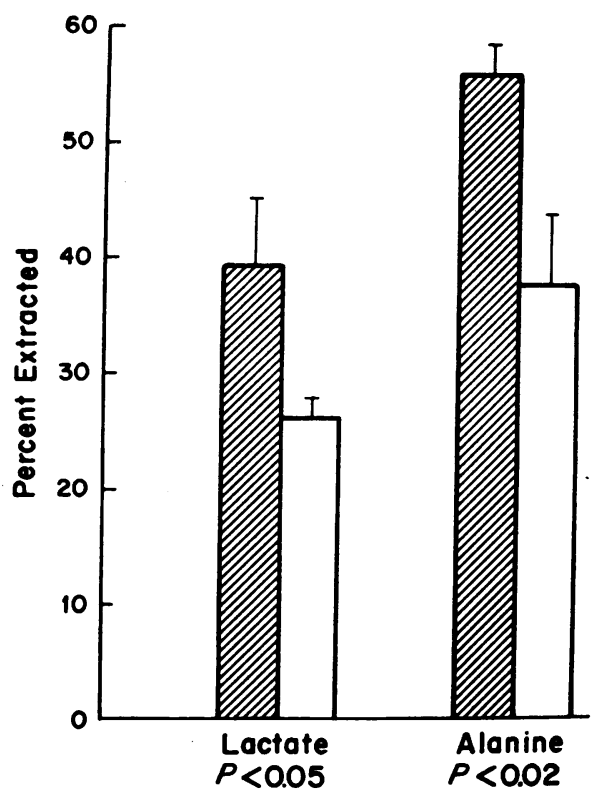

FIGURE 1 Fractional extraction by the splanchnic vascular bed in obese subjects (cross-hatched bars) and in nonobese controls (open bars) of lactate and alanine. Mean values $\pm \mathrm{SE}$ are shown. $P$ values indicate the significance of differences between obese and control subjects.

TABLE V

Influence of Glucose Infusion on Arterial Levels of Insulin and Glucagon and on Arterial Concentration and Splanchnic Output of Glucose*

\begin{tabular}{|c|c|c|c|c|c|c|c|c|}
\hline & \multicolumn{8}{|c|}{ Glucose infusion, $\min$} \\
\hline & Basalt & 5 & 10 & 15 & 22.5 & 30 & 37.5 & 45 \\
\hline \multicolumn{9}{|l|}{ Controls, $144 \pm 4 \mathrm{mg} / \mathrm{min} \S$} \\
\hline Arterial glucose, $m \cdot M$ & $4.27 \pm 0.09$ & $4.54 \pm 0.16$ & $4.67 \pm 0.17$ & $4.80 \pm 0.17$ & $4.94 \pm 0.16$ & $5.05 \pm 0.16$ & $5.17 \pm 0.16$ & $5.20 \pm 0.16$ \\
\hline Arterial insulin, $\mu U / m l$ & $12.9 \pm 1.4$ & $21.6 \pm 2.0$ & $23.4 \pm 2.3$ & $17.8 \pm 2.9$ & - & $18.8 \pm 2.5$ & - & $21.0 \pm 2.5$ \\
\hline Arterial glucagon, $p g / m l$ & $79.8 \pm 12.5$ & $89.7 \pm 24.1$ & $82.1 \pm 24.6$ & $68.8 \pm 19$ & - & $81.4 \pm 20.1$ & - & $76.7 \pm 22.0$ \\
\hline $\begin{array}{l}\text { Splanchnic glucose } \\
\text { Output, } \| \mathrm{mmol} / \mathrm{min}\end{array}$ & $1.23 \pm 0.11$ & $1.05 \pm 0.22$ & $0.90 \pm 0.21$ & $0.70 \pm 0.18$ & $0.44 \pm 0.09$ & $0.42 \pm 0.11$ & $0.37 \pm 0.11$ & $0.30 \pm 0.05$ \\
\hline $\mathrm{EHBF}, \mathbb{I} \mathrm{ml} / \mathrm{min}$ & $1,359 \pm 51$ & $1,334 \pm 83$ & $1,298 \pm 69$ & $1,310 \pm 77$ & $1,277 \pm 77$ & $1,274 \pm 75$ & $1,270 \pm 86$ & $1,288 \pm 86$ \\
\hline \multicolumn{9}{|l|}{ Obese, $75 \mathrm{mg} / \mathrm{min} \S$} \\
\hline Arterial glucose, $m M$ & $4.56 \pm .02$ & $4.61 \pm 0.20$ & $4.82 \pm 0.16$ & $4.89 \pm 0.19$ & $5.00 \pm 0.24$ & $5.05 \pm 0.26$ & $5.10 \pm 0.26$ & $5.16 \pm 0.28$ \\
\hline Arterial insulin, $\mu U / m l$ & $28.1 \pm 3.1$ & $45.4 \pm 7.5$ & $43.4 \pm 9.1$ & $40.8 \pm 7.2$ & - & $46.1 \pm 8.9$ & - & $44.8 \pm 10.9$ \\
\hline Arterial glucagon, $p g / m l$ & $76.2 \pm 9.2$ & $74.0 \pm 4.0$ & $63.2 \pm 10.3$ & $63.4 \pm 8.5$ & - & $69.6 \pm 8.1$ & - & $68.2 \pm 9.3$ \\
\hline $\begin{array}{l}\text { Splanchnic glucose } \\
\text { Output, } \| \mathrm{mmol} / \mathrm{min}\end{array}$ & $1.35 \pm 0.25$ & $1.10 \pm 0.23$ & $0.90 \pm 0.18$ & $0.81 \pm 0.16$ & $1.04 \pm 0.25$ & $1.22 \pm 0.29$ & $1.06 \pm 0.27$ & $1.13 \pm 0.27$ \\
\hline $\mathrm{EHBF}, \llbracket m l / \min$ & $1,588 \pm 41$ & $1,538 \pm 85$ & $1,528 \pm 74$ & $1,540 \pm 82$ & $1,562 \pm 112$ & $1,559 \pm 133$ & $1,545 \pm 135$ & $1,526 \pm 128$ \\
\hline \multicolumn{9}{|l|}{ Obese, $150 \mathrm{mg} / \mathrm{min} \S$} \\
\hline Arterial glucose, $m \cdot M$ & $4.61 \pm 0.15$ & $5.29 \pm 0.25$ & $5.26 \pm 0.22$ & $5.30 \pm 0.17$ & $5.27 \pm 0.22$ & $5.38 \pm 0.17$ & $5.41 \pm 0.19$ & $5.51 \pm 0.20$ \\
\hline Arterial insulin, $\mu U / m l$ & $25.5 \pm 1.7$ & $57.0 \pm 10.0$ & $48.3 \pm 8.6$ & $54.1 \pm 9.5$ & - & $73.9 \pm 17.2$ & - & $51.7 \pm 13.7$ \\
\hline Arterial glucagon, $\mathrm{pg} / \mathrm{ml}$ & $71.2 \pm 10.1$ & $55.0 \pm 7.1$ & $62.0 \pm 6.3$ & $69.2 \pm 7.5$ & - & $63.0 \pm 6.1$ & - & $65.5 \pm 8.0$ \\
\hline $\begin{array}{l}\text { Splanchnic glucose } \\
\text { Output, } \| \mathrm{mmol} / \mathrm{min}\end{array}$ & $1.34 \pm 0.20$ & $0.81 \pm 0.37$ & $0.70 \pm 0.34$ & $0.66 \pm 0.30$ & $0.53 \pm 0.30$ & $0.41 \pm 0.23$ & $0.30 \pm 0.12$ & $0.42 \pm 0.21$ \\
\hline $\mathrm{EHBF}, \mathbb{\eta} \mathrm{ml} / \mathrm{min}$ & $1,580 \pm 54$ & $1,544 \pm 39$ & $1,508 \pm 32$ & $1,544 \pm 66$ & $1,567 \pm 72$ & $1,572 \pm 98$ & $1,594 \pm 83$ & $1,577 \pm 75$ \\
\hline
\end{tabular}

* Data are presented as the mean $\pm \mathrm{SE}$.

$\ddagger$ Basal values represent the mean of two to three observations in each subjects at 10-15 min intervals before the infusion of glucose.

\$ Glucose infusion rate. In the control group the infusion rate was calculated as $2 \mathrm{mg} / \mathrm{kg}$ of body $\mathrm{wt} / \mathrm{min}$.

|| Calculated from arterio-hepatic venous differences and estimated hepatic blood flow.

II Estimated hepatic blood flow. 

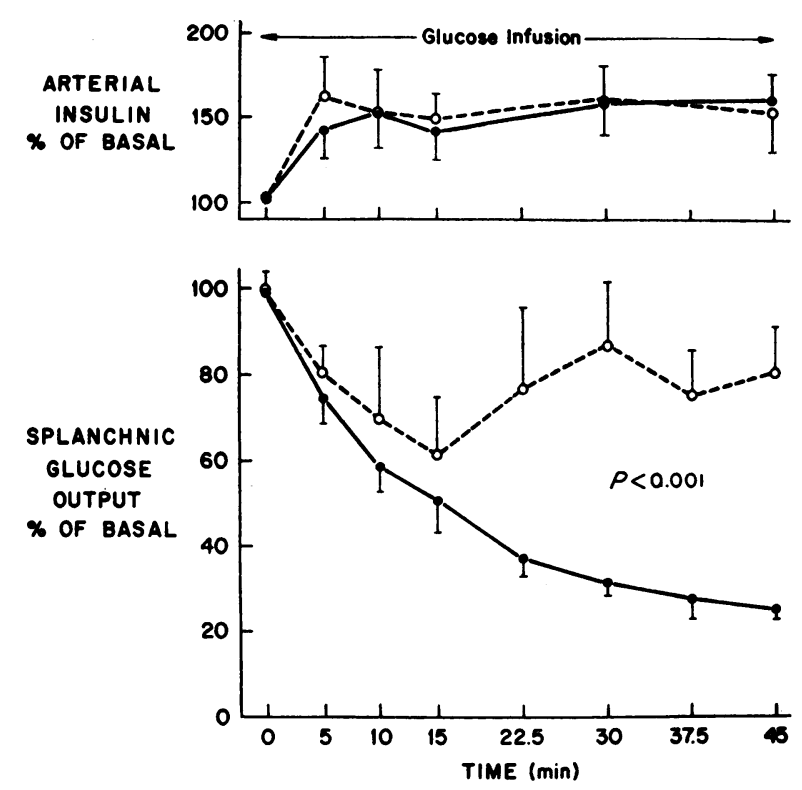

FIGURE 2 Splanchnic glucose output in obese (open circles) and control (closed circles) subjects during the infusion of glucose at rates causing an equivalent increase in arterial insulin concentrations. Glucose was infused at a rate of $144 \pm 4 \mathrm{mg} / \mathrm{min}(2 \mathrm{mg} / \mathrm{kg} / \mathrm{min})$ in the control group and at a rate of $75 \mathrm{mg} / \mathrm{min}$ in the obese group. The $P$ value represents the significance of the difference in response of splanchnic glucose output over the course of the infusion (analysis of variance). Arterial glucose levels (Table V) did not differ between the two groups during the infusion.

blood glucose concentration of $0.9 \mathrm{mmol} / \mathrm{liter}(16 \mathrm{mg} /$ $100 \mathrm{ml}$ ) and in a 50-60\% rise in arterial insulin levels. In association with these small increments in circulating glucose and insulin, splanchnic glucose production fell as expected (7), to $0.3 \mathrm{mmol} / \mathrm{min}$, representing a decline of $75 \%$.

In the obese subjects, infusion of glucose at a rate of $75 \mathrm{mg} / \mathrm{min}$ resulted in an elevation in blood glucose of $0.6 \mathrm{mmol} /$ liter $(11 \mathrm{mg} / 100 \mathrm{ml})$, and a $50-60 \%$ increase in arterial insulin (Table V). This rate of infusion was selected for the obese subjects so as to simulate the insulin rise in the control group. Despite the comparability in the increase in insulin in the two groups, a much smaller diminution in splanchnic glucose production was observed in the obese subjects (Fig. 2). Thus mean splanchnic glucose output in the obese at no time fell below $0.8 \mathrm{mmol} / \mathrm{min}$ (Table $\mathrm{V}$ ), representing a maximal decline of $38 \%$. Over the entire course of the infusion the extent of inhibition of splanchnic glucose output was significantly less in the obese subjects than in controls $(P<0.001$, analysis of variance; Fig. 2). In absolute terms, the mean maximal decline in splanchnic glucose output was $1.01 \pm 0.16 \mathrm{mmol} / \mathrm{min}$ in the controls and $0.42 \pm 0.09 \mathrm{mmol} / \mathrm{min}$ in the obese group $(P<$
0.01). At termination of the infusion, the rate of splanchnic glucose production (which was comparable in the two groups in the basal state), was significantly higher in the obese group than in the controls $(1.13 \pm 0.27$ $\mathrm{mmol} / \mathrm{min}$ vs. $0.30 \pm 0.05, P<0.01)$. It should be noted however, that during the initial 5-15 $\mathrm{min}$ of the 75 $\mathrm{mg} / \mathrm{min}$ glucose infusion the fall in splanchnic glucose output was comparable to the control group (Fig. 2).

Administration of glucose to obese subjects at a rate of $150 \mathrm{mg} / \mathrm{min}$ resulted in an elevation of blood glucose of $0.9 \mathrm{mmol} / \mathrm{liter}(16 \mathrm{mg} / 100 \mathrm{ml})$, and in a $75 \%$ reduction in splanchnic glucose production (Table V). The absolute rate of splanchnic glucose output in the obese subjects during the course of the $150 \mathrm{mg} / \mathrm{min}$ glucose infusion was not significantly different from that observed during the glucose infusion in the control group (Table V). This rate of infusion thus resulted in an inhibition in splanchnic glucose output which was comparable to the controls (Fig. 3). In contrast to the similarity in changes in splanchnic glucose balance, the insulin response in the obese subjects was greater than that observed in the control group (Table V). Over the entire course of the $150 \mathrm{mg} / \mathrm{min}$ glucose infusion the percent rise in insulin (Fig. 3) was significantly greater
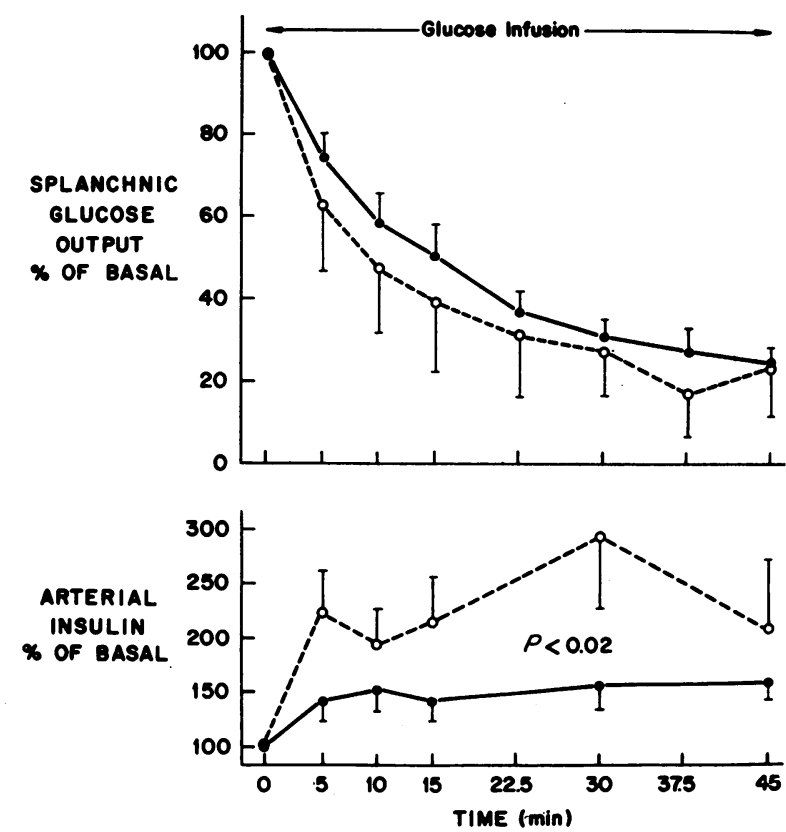

Figure 3 Changes in arterial insulin from basal concentration in obese (open circles) and control (closed circles) subjects during the infusion of glucose at rates associated with equivalent inhibition of splanchnic glucose output. Glucose was infused at a rate of $144 \pm 4 \mathrm{mg} / \mathrm{kg}$ in the controls and a rate of $150 \mathrm{mg} / \mathrm{min}$ in the obese group. The $P$ value refers to the significance of the difference between the insulin response in obese and control subjects (analysis of variance). 
TABLE VI

Splanchnic Exchange of Plasma Amino Acids after the Infusion of Glucose in Obese and Control Subjects*

\begin{tabular}{lccccc}
\hline & \multicolumn{2}{c}{ Obese } & \multicolumn{2}{c}{ Controls } \\
\cline { 2 - 3 } \cline { 5 - 6 } & Basal & $\begin{array}{c}\text { Glucose } \\
\text { infusion } \ddagger\end{array}$ & & Basal & $\begin{array}{c}\text { Glucose } \\
\text { infusion } \neq\end{array}$ \\
\hline Taurine & $-4.2 \pm 4.0$ & $0.6 \pm 1.6$ & $0.9 \pm 2.4$ & $3.4 \pm 3.6$ \\
Aspartic acid & $-2.0 \pm 0.7$ & $-1.8 \pm 0.4$ & & $1.1 \pm 1.3$ & $0.1 \pm 2.3$ \\
Threonine & $17.0 \pm 2.8$ & $14.5 \pm 2.6$ & & $11.2 \pm 4.0$ & $8.0 \pm 9.2$ \\
Serine & $24.8 \pm 5.4$ & $21.5 \pm 4.8$ & & $22.5 \pm 5.7$ & $14.4 \pm 0.7$ \\
Proline & $4.9 \pm 3.3$ & $1.0 \pm 3.8$ & & $8.9 \pm 7.6$ & $6.6 \pm 12.4$ \\
Citrulline & $-12.5 \pm 2.5$ & $-12.8 \pm 2.3$ & & $-8.3 \pm 2.6$ & $-1.2 \pm 5.7$ \\
Glycine & $16.3 \pm 4.2$ & $13.0 \pm 4.0$ & & $6.8 \pm 8.9$ & $8.9 \pm 14.6$ \\
Alanine & $136.2 \pm 14.8$ & $128.5 \pm 16.2$ & & $58.2 \pm 9.8$ & $63.7 \pm 9.7$ \\
$\alpha$-NH & $1.2 \pm 1.1$ & $0.4 \pm 0.3$ & & $1.4 \pm 1.1$ & $1.4 \pm 1.9$ \\
Valine & $-3.6 \pm 2.3$ & $-2.6 \pm 2.9$ & & $-2.7 \pm 8.3$ & $3.3 \pm 13.8$ \\
Cystine & $0.2 \pm 2.9$ & $2.3 \pm 3.5$ & & $3.0 \pm 4.6$ & $2.8 \pm 11.8$ \\
Methionine & $4.7 \pm 1.0$ & $4.6 \pm 0.5$ & & $4.3 \pm 1.7$ & $2.4 \pm 1.9$ \\
Isoleucine & $-1.2 \pm 2.0$ & $-0.1 \pm 1.3$ & & $-1.6 \pm 2.4$ & $-0.1 \pm 3.3$ \\
Leucine & $-0.3 \pm 3.4$ & $-0.1 \pm 2.6$ & & $-4.0 \pm 5.5$ & $-0.7 \pm 7.4$ \\
Tyrosine & $2.1 \pm 1.0$ & $8.3 \pm 1.1$ & & $6.5 \pm 2.3$ & $8.5 \pm 2.0$ \\
Phenylalanine & $3.9 \pm 1.0$ & $3.6 \pm 1.2$ & & $3.3 \pm 1.3$ & $3.3 \pm 2.4$ \\
\hline
\end{tabular}

* Data are presented as mean $\pm \mathrm{SE}$, in micromoles per minute.

$\ddagger$ Samples obtained after a 45 - $\mathrm{min}$ infusion of glucose at a rate of $144 \pm 4 \mathrm{mg} / \mathrm{min}$ in the controls and $150 \mathrm{mg} / \mathrm{min}$ in the obese group.

in the obese group than in controls $(P<0.02$, analysis of variance). The mean maximal increment in insulin levels was $208 \pm 65 \%$ in the obese group vs. $82 \pm 15 \%$ in the controls $(0.05<P<0.10)$. Comparable inhibition of splanchnic glucose output thus was associated with a disproportionately greater increment in arterial insulin concentration in obese as compared with control subjects. The absolute concentration of arterial insulin in the obese group was significantly greater during the course of the $150 \mathrm{mg} / \mathrm{min}$ infusion as compared to the 75 $\mathrm{mg} / \mathrm{min}$ infusion ( $P<0.05$, analysis of variance).

In the control group and in the obese subjects the glucose infusions failed to cause a consistent change in arterial glucagon concentration (Table V). Estimated hepatic blood flow declined $7 \%$ in the control group and remained unchanged in the obese subjects (Table V). Splanchnic uptake of amino acids was not influenced by the glucose infusion in the control or obese subjects (Table VI). The latter findings are in accord with previous observations in which a similar rate of glucose infusion was employed (7).

\section{DISCUSSION}

In the present study the hepatic venous catheter technique has been employed to determine the effect of obesity on hepatic glucose production and precursor uptake in the basal state and after stimulation of endoge- nous insulin secretion. While this method measures net splanchnic balance rather than actual hepatic exchange, previous data in normal subjects utilizing blood samples obtained from the portal vein indicate that splanchnic balances underestimate the true hepatic production of glucose by less than $5 \%$ (11). While the possibility cannot be excluded that increased mesenteric fat in obese subjects may increase arterial-portal venous differences for glucose, this is unlikely to be of quantitative significance since the overall contribution of the entire mass of adipose tissue to total glucose turnover is less than $5 \%$ (19).

In the basal state splanchnic glucose release in obese subjects was comparable with the control group. This finding is in agreement with previous reports in which glucose turnover was determined by means of radioisotopic studies employing $\left[1-{ }^{14} \mathrm{C}\right]$ glucose $(20,21)$. In contrast to the similarity in overall glucose production, splanchnic uptake of glucose precursors was significantly augmented in the obese group, suggesting that the contribution from gluconeogenesis to total hepatic glucose release is increased in obesity. Thus splanchnic uptake of lactate, alanine, and glycerol was increased by 50-130\%. With respect to alanine, augmented splanchnic uptake was demonstrable on the basis of measurements with whole blood as well as plasma. Furthermore, inasmuch as arterial-portal venous differences of both whole 
TABLE VII

Balance of Glucose and Glucogenic Substrates across the Splanchnic Vascular Bed in the Basal State in Obese and Control Subjects

\begin{tabular}{lcc}
\hline & Obese & Controls \\
\hline $\begin{array}{l}\text { Glucose production* } \\
\text { Uptake of }\end{array}$ & 1.10 & 1.23 \\
(1) Lactate $\ddagger$ & 0.190 & 0.110 \\
(2) Pyruvate & 0.002 & 0.011 \\
(3) Glycerol $\ddagger$ & 0.052 & 0.034 \\
(4) Alanine $\S$ & 0.090 & 0.054 \\
(5) Other amino acids $\ddagger \|$ & 0.032 & 0.028 \\
Sum of 1-5 & 0.366 & 0.237 \\
Percent of glucose production & 33 & 19 \\
\end{tabular}

* Data are presented in millimoles per minute.

$\ddagger$ Expressed as glucose equivalents in millimoles per minute. \$ Based on whole blood measurements.

|| Sum of splanchnic uptake of threonine, serine, glycine, methionine, tyrosine, and phenylalanine (Table III).

blood and plasma indicate a net release of alanine from the gut (12), the current findings underestimate rather than overestimate the true hepatic uptake of this amino acid.

In Table VII the balance data for glucose and glucose precursors across the splanchnic bed is shown. On the basis of net precursor uptake it can be seen that $19 \%$ of hepatic glucose output can be accounted for by gluconeogenesis in the controls, whereas over $30 \%$ was derivable from precursor substrates in the obese group. Supporting an increased rate of gluconeogenesis is the elevation in splanchnic consumption of oxygen and FFA observed in the obese subjects (Table IV). In this regard, it is noteworthy that studies with isotopic alanine (22), lactate (23), and glycerol (24) have also demonstrated increased incorporation of these substrates into glucose in obesity. In addition, an augmented gluconeogenic rate has been suggested in obese subjects on the basis of their resistance to alcohol hypoglycemia (25).

It is of interest that the increase in gluconeogenic precursor uptake observed in obese subjects corresponds closely to that previously demonstrated in insulin-dependent, nonobese diabetic patients (8). In the latter group, as in the obese subjects, $33 \%$ of glucose output is attributable to precursor consumption as compared to $19 \%$ in controls. Furthermore, in obesity as well as in diabetes (8), the increase in substrate uptake is due in part, to augmented splanchnic fractional extraction. Thus, whereas $38 \%$ of the alanine and $26 \%$ of the lactate presented to the liver was extracted by the control group, 55 and $39 \%$, respectively, were taken up by the obese subjects (Fig. 1). The similarity to diabetes with respect to increased hepatic uptake of gluconeogenic pre- cursors despite the presence of basal hyperinsulinemia in the obese group, suggests that the liver is resistant to insulin in obesity. That peripheral resistance to insulin may also contribute to increased gluconeogenesis in obesity is indicated by the elevated circulating levels and splanchnic uptake of glycerol and FFA.

The question of altered hepatic responsiveness to insulin may also be raised by the response to glucose infusion. In accordance with previous data (7), administration of glucose at a rate of $144 \mathrm{mg} / \mathrm{min}(2 \mathrm{mg} / \mathrm{kg} / \mathrm{min})$ to the control subjects resulted in a $75 \%$ inhibition in splanchnic glucose output despite no more than a $50-60 \%$ increase in arterial insulin levels. In contrast, infusion of glucose in obese subjects at a rate $(75 \mathrm{mg} / \mathrm{min})$ eliciting a comparable increase $(50-60 \%)$ in arterial insulin concentration resulted in a much smaller decline in splanchnic glucose output (Fig. 2). In addition, infusion of glucose at $150 \mathrm{mg} / \mathrm{min}$ in obese subjects elicited a $75 \%$ inhibition in splanchnic glucose output which was comparable with controls, but was achieved only in the face of a significantly greater rise in arterial insulin (Fig. 3). These data are thus compatible with diminished hepatic sensitivity to insulin, provided the relationships observed between obese and control subjects with respect to arterial insulin levels apply to portal vein concentrations as well. Direct measurements of portal vein insulin levels were not feasible in the current study. A direct relationship between portal and peripheral insulin levels over a wide range of insulin concentrations has been demonstrated in nonobese subjects (26). It may be argued however, that inasmuch as binding of insulin by liver cell membranes is reduced in obesity (27), a substantial portion of insulin escapes hepatic degradation so that the concentration of insulin in the portal vein is not proportionately elevated. On the other hand, inasmuch as the liver is a major site of insulin degradation, and since insulin turnover rates are increased rather than decreased in obesity (28), the possibility of diminished hepatic degradation of insulin in obesity and an accompanying decrease in the portal peripheral gradient is unlikely.

The possibility must also be considered that differences in arterial glucose or glucagon levels contribute to the altered responsiveness of splanchnic glucose balance observed in obesity. That this is unlikely is indicated by the fact that arterial glucose concentration during the $75 \mathrm{mg} / \mathrm{min}$ infusion in the obese subjects was virtually identical with the levels observed during glucose infusion in controls (Table V). Furthermore, arterial glucagon levels were similar in the two groups in the basal state (Table II), and were uninfluenced by the small increments in arterial glucose induced by the glucose infusions in both groups (Table V). Nevertheless, factors other than changes in insulin levels may he of some 
inportance in determining the hepatic response to infusion of glucose. Thus in the obese subjects the absolute increment in mean insulin concentration at termination of the $150 \mathrm{mg} / \mathrm{min}$ infusion was only $65 \%$ greater than that observed at termination of the $75 \mathrm{mg} / \mathrm{min}$ infusion yet was accompanied by a fourfold greater decline in splanchnic glucose output (Table V).

The question may be raised as to whether the infusion of glucose influenced peripheral glucose utilization in addition to its effects on splanchnic glucose output. Although peripheral glucose uptake was not directly measured, the glucose utilization rate may be estimated from the available data. Since extrahepatic glucose production is negligible in postabsorptive man (29), peripheral glucose utilization must equal splanchnic glucose output plus the glucose infused minus the glucose accumulation in body fluids. Since the glucose infusion rate was maintained at a constant rate, peripheral glucose utilization may be estimated from the data in

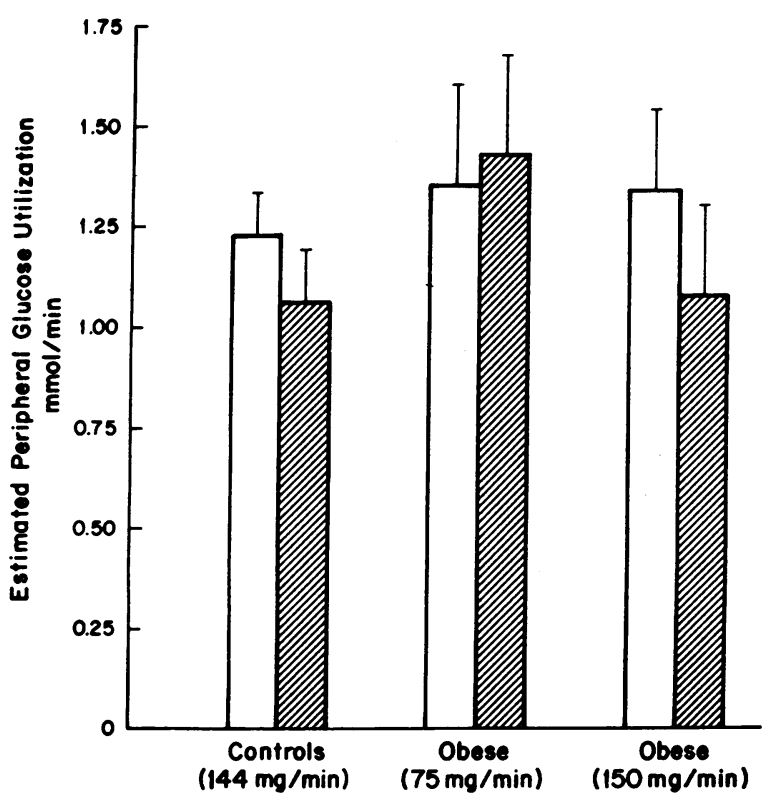

FIGURE 4 Estimated peripheral glucose utilization rate (mean $\pm \mathrm{SE}$ ) in the basal state (open bars) and after a 45-min glucose infusion (cross-hatched bars) in control and obese subjects. The figures in parentheses represent the glucose infusion rates for each of the groups. Estimated peripheral glucose utilization $=$ splanchnic glucose output + glucose infused-glucose accumulation in body fluids. Glucose accumulation in body fluids was calculated as the product of the increase in arterial glucose concentration and the glucose space. The glucose space was taken to be $25 \%$ of body weight in the controls $(9,34)$, and $15 \%$ of body weight in the obese group $(34,35)$. In all three groups the mean estimated glucose utilization rate after the 45-min glucose infusion was not significantly different from the value observed in the basal state $(P>$ $0.1)$.
Table V. As shown in Fig. 4, in the control group and in the obese subjects the mean estimated rate of glucose utilization was not significantly different at termination of the infusion from that observed in the basal state. These data are in accord with previous findings in normal subjects (7) and prediabetics (30) in whom glucose was infused at similar rates. Furthermore these observations support the conclusion advanced previously $(7,30)$ that the liver is the primary site of action of small increments in endogenous insulin.

The changes in amino acid concentration noted in the current study are in agreement with previous observations of elevations in the branched chain amino acids in obesity $(31,32)$. However, in contrast to earlier observations in which venous blood was utilized $(31,32)$, an elevation in arterial alanine was also noted. In previous studies a relation between arterial alanine and pyruvate levels has been observed in the resting state and during exercise (10). In addition, it has been suggested that alanine formation and its accumulation in arterial blood depend in part, on peripheral glycolysis and the rate of pyruvate production $(10,18,33)$. It is noteworthy in this regard that arterial pyruvate levels were also elevated in the obese subjects (Table II). Furthermore, Rabinowitz and Zierler reported an increase in basal uptake of glucose by resting muscle in obesity (4). Thus hyperalaninemia in obesity may be a consequence of increased muscle glycolysis and greater availability of pyruvate for transamination.

\section{ACKNOWLEDGMENTS}

This work was supported in part by U. S. Public Health Service Grant AM 13526, by Grants 19X-3108 and 19X722 from the Swedish Medical Research Council, and by a grant from the Karolinska Institute.

\section{REFERENCES}

1. Karam, J. H., G. M. Grodsky, and P. H. Forsham. 1963. Excessive insulin response to glucose in obese subjects as measured by immunochemical assay. Diabetes. 12: 197.

2. Bagdade, J. D., E. L. Bierman, and D. Porte, Jr. 1967. The significance of basal insulin levels in the evaluation of the insulin response to glucose in diabetic and non-diabetic subjects. J. Clin. Invest. 46: 1549.

3. Salans, L. B., J. L. Knittle, and J. Hirsch. 1968. The role of adipose cell size and adipose tissue insulin sensitivity in the carbohydrate intolerance of human obesity. J. Clin. Invest. 47: 153.

4. Rabinowitz, D., and K. L. Zierler. 1962. Forearm metabolism in obesity and its response to intra-arterial insulin: characterization of insulin resistance and evidence for adaptive hyperinsulinism. J. Clin. Invest. 41: 2173.

5. Ogilvie, R. F. 1935. Sugar tolerance in obese subjects: review of 65 cases. Q. J. Med. $4: 345$.

6. Madison, L. L. 1969. Role of insulin in the hepatic handling of glucose. Arch. Intern. Med. 123: 284. 
7. Felig, P., and J. Wahren. 1971. Influence of endogenous insulin secretion on splanchnic glucose and amino acid metabolism. J. Clin. Invest. 50: 1702 .

8. Wahren, J., P. Felig, E. Cerasi, and R. Luft. 1972. Splanchnic and peripheral glucose and amino acid metabolism in diabetes mellitus. J. Clin. Invest. 51: 1870.

9. Franckson, J. R. M., H. A. Ooms, R. Bellens, V. Conard, and P. A. Bastenie. 1962. Physiologic significance of the intravenous glucose tolerance test. Metab. (Clin. Exp.). 11: 482.

10. Felig, P., and J. Wahren. 1971. Amino acid metabolism in exercising man. J. Clin. Invest. 50: 2703.

11. Wahren, J., P. Felig, G. Ahlborg, and L. Jorfeldt. 1971. Glucose metabolism during leg exercise in man. J. Clin. Invest. 50: 2715.

12. Felig, P., J. Wahren, and L. Raf. 1973. Evidence of inter-organ amino-acid transport by blood cells in humans. Proc. Natl. Acad. Sci. U. S. A. 70: 1775.

13. Hagenfeldt, L. 1966. A gas chromatographic method for the determination of individual free fatty acids in plasma. Clin. Chim. Acta. 13: 266.

14. Snedecor, G. W., and G. W. Cochrane. 1969. Statistical Methods. Iowa State University Press, Ames, Iowa. 6th edition.

15. Zimmer, G. 1966. Regulation of serum fatty acids, free glycerol, and acetoacetate during prolonged fasting in obese and lean people. Nature (Lond.). 212: 1202.

16. Opie, L. H., and P. G. Walfish. Plasma free fatty acid concentrations in obesity. 1963. N. Engl. J. Med. 268: 757.

17. Felig, P., O. E. Owen, J. Wahren, and G. F. Cahill, Jr. 1969. Amino acid metabolism during prolonged starvation. J. Clin. Invest. 48: 584.

18. Felig, P., T. Pozefsky, E. Marliss, and G. F. Cahill, Jr. 1970. Alanine: key role in gluconeogenesis. Science (Wash. D. C.). 167: 1003.

19. Galton, D. J., and J. P. D. Wilson. 1970. Effects of diabetes on glucose metabolism in human adipose tissue. In Adipose Tissue, Regulation and Metabolic Functions. B. Jeanrenaud and D. Hepp, editors. Academic Press Inc. Ltd., London. 172

20. Kreisberg, R. A. 1968. Glucose metabolism in normal and obese subjects. Effect of phenformin. Diabetes. 17: 481.

21. Kreisberg, R. A. 1968. Kinetics of glucose utilization in obesity: the effect of phenformin Ann. N.Y. Acad. Sci. 148: 743 .
22. Shigeta, Y., N. Oji, M. Hoshi, and M. Kang. 1965. Fatty acid synthesis and gluconeogenesis in rats fed a high calorie diet. Metab. (Clin. Exp.). 15: 761.

23. Shreeve, W. W., M. Hoshi, N. Ohi, Y. Shigeta, and H. Abe. 1968. Insulin and the utilization of carbohydrate in obesity. Am. J. Clin. Nutr. 21: 1404.

24. Bortz, W. M., P. Paul, A. C. Haff, and W. L. Holmes. 1972. Glycerol turnover and oxidation in man. J. Clin. Invest. $51: 1537$.

25. Arky, R. A., and N. Freinkel. 1966. Alcohol hypoglycemia. V. Alcohol infusion to test gluconeogenesis in starvation, with special reference to obesity. N. Engl. J. Med. 274 : 426.

26. Blackard, W. G., and N. C. Nelson. 1970. Portal and peripheral vein immunoreactive insulin concentrations before and after glucose infusion. Diabetes. 19: 302

27. Kahn, C. R, D. M. Neville, Jr., and J. Roth. 1973. Insulin-receptor interaction in the obese-hyperglycemic mouse. J. Biol. Chem. $248: 244$.

28. Genuth, S. M. 1972. Metabolic clearance of insulin in man. Diabetes. $21: 1003$.

29. Cahill, G. F., Jr., and O. E. Owen. 1968. Some observations on carbohydrate metabolism in man. In Carbohydrate Metabolism and Its Disorders. F. Dickens, P. J. Randle, and W. J. Whelan, editors. Academic Press, Inc., New York. 1: 497.

30. Wahren, J., P. Felig, E. Cerasi, R. Luft, and R. Hendler. 1973. Splanchnic glucose production and its regulation in healthy monozygotic twins of diabetics. Clin. Sci. (Oxf.). 44: 493.

31. Felig, P., E. Marliss, and G. F. Cahill, Jr. 1969. Plasma amino acid levels and insulin secretion in obesity. $N$. Engl. J. Med. 281: 811.

32. Adibi, S. A. 1968. Influence of dietary deprivation on plasma concentration of free amino acids in man. $J$. Appl. Physiol. 25: 52.

33. Felig, P. 1973. The glucose-alanine cycle. Metab. (Clin. Exp.). 22: 179 .

34. Franckson, J. R. M., W. Malaise, Y. Arnould, E. Rasio, H. A. Ooms, E. Balasse, V. Conard, and P. A. Bastenie. 1966. Glucose kinetics in human obesity. Diabetologia. 2 : 96.

35. Paul, P., and W. M. Bortz. 1969. Turnover and oxidation of plasma glucose in lean and obese humans. Metab. (Clin. Exp.). 18: 570 . 